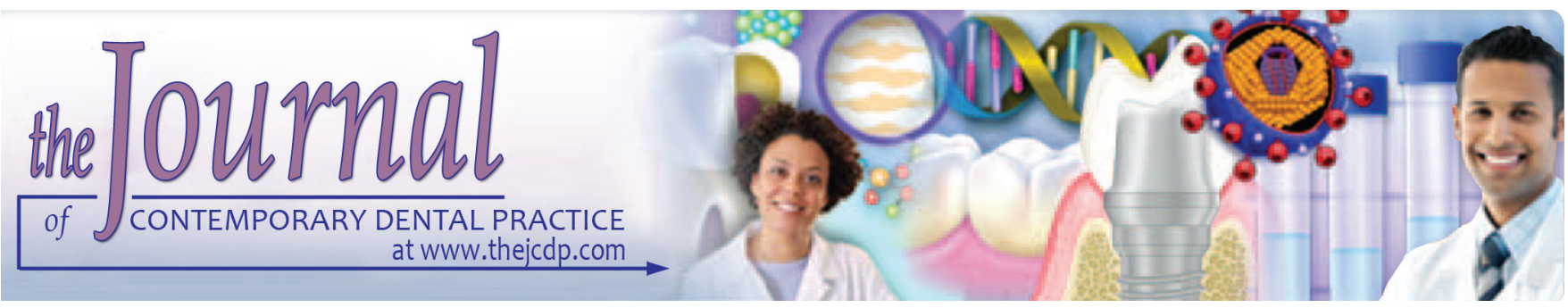

\title{
Evaluating the Surface Characteristics of Stainless Steel, TMA, Timolium, and Titanium-niobium Wires: An in vivo Scanning Electron Microscope Study
}

${ }^{1} \mathrm{~K}$ Pradeep Babu, ${ }^{2} \mathrm{~V}$ Naga Keerthi, ${ }^{3}$ Deepika Madathody, ${ }^{4} \mathrm{~A}$ Laxmi Prasanna, ${ }^{5}$ Vidhya Gopinath

${ }^{6} \mathrm{M}$ Senthil Kumar, ${ }^{7} \mathrm{~A}$ Nanda Kumar

\begin{abstract}
Background: Recent metallurgical research and advancement in material science has benefited orthodontists in the selection of an appropriate wire size and alloy type, which is necessary to provide an optimum and predictable treatment results. The purpose of the study was to clinically evaluate and compare the surface characteristics of $16 \times 22$ stainless steel, Titanium molybdenum alloy, timolium, and titanium-niobium before and after placing them in a patient's mouth for 3 months using a scanning electron microscope (SEM).
\end{abstract}

Materials and methods: The total sample size was 40 , which were divided into four groups (group 1 - stainless steel wires, 10 samples, group 2 - TMA wires, 10 samples, group 3 - timolium wires, 10 samples, and group 4 - titanium-niobium wires, 10 samples), and these were further subdivided into 5 each. The first subgroup of five samples was placed in the patient's mouth and was evaluated under SEM, and another subgroup of five samples was directly subjected to the SEM.

Results: Scanning electron microscopic evaluation of surface characteristics of unused $16 \times 22$ rectangular stainless steel wire under $500 \times$ magnification showed an overall smooth surface. Stainless steel wire samples placed in the patient's mouth showed

\footnotetext{
${ }^{1,2,6}$ Department of Orthodontics and Dentofacial Orthopedics Indira Gandhi Institute of Dental Sciences, Puducherry, India

${ }^{3}$ Department of Orthodontics and Dentofacial Orthopedics, Mar Baselios Dental College, Ernakulam, Kerala, India

${ }^{4}$ Department of Orthodontics and Dentofacial Orthopedics Paneeniya Institute of Dental Sciences, Hyderabad, Telangana India

${ }^{5}$ Department of Prosthodontics, Saveetha Dental College Chennai, Tamil Nadu, India

${ }^{7}$ Department of Orthodontics and Dentofacial Orthopedics Meenakshi Ammal Dental College, Chennai, Tamil Nadu, India

Corresponding Author: K Pradeep Babu, Reader, Department of Orthodontics and Dentofacial Orthopedics, Indira Gandhi Institute of Dental Sciences, Puducherry, India, Phone: +919908645099, e-mail: drpradeepkommi@gmail.com
}

black hazy patches, which may be interoperated as areas of stress. TMA unused wires showed multiple small voids of areas and small craters with fewer elevated regions. The TMA wire samples placed in the patient's mouth showed black hazy patches and prominent ridges, making the wire rougher. Timolium unused archwires showed heavy roughness and voids, whereas wires tested in the patient's mouth showed homogeneous distribution of deep cracks and craters. Unused titanium-niobium archwires showed uniform prominent striations and ridges with occasional voids, whereas wires used in the patient's mouth showed prominent huge voids that could be interpreted as maximum stress areas.

Conclusion: Stainless steel (group 1) used and unused wires showed smooth surface characteristics when compared with all the other three groups followed by timolium, which was superior to titanium-niobium wires and TMA wires.

Clinical significance: Timolium wires are superior to titaniumniobium wires and TMA wires.

Keywords: Scanning electron microscope, Stainless steel wires, Surface characteristics, Timolium wires, Titanium-niobium wires, TMA wires.

How to cite this article: Babu KP, Keerthi VN, Madathody D, Prasanna AL, Gopinath V, Kumar MS, Kumar AN. Evaluating the Surface Characteristics of Stainless Steel, TMA, Timolium, and Titanium-niobium Wires: An in vivo Scanning Electron Microscope Study. J Contemp Dent Pract 2016;17(5):372-376.

Source of support: Nil

Conflict of interest: None

\section{INTRODUCTION}

Recent metallurgical research and advancement in material science has led to the development of an array of new orthodontic wire materials, which has increased the versatility of orthodontic therapy. The selection of an appropriate wire size and alloy type is necessary to provide optimum and predictable treatment results. Every orthodontist should therefore be well versed 
with the mechanical properties and the relevant clinical application of these properties. ${ }^{1}$

Until the 1920s, the only orthodontic wires available were made of gold. Austenitic stainless steel was introduced as an orthodontic wire in $1929,{ }^{2}$ which stayed as the main archwire in orthodontics. Beta-titanium was available in the $1980 \mathrm{~s},{ }^{3,4}$ which had distinctive features of good spring back, low force delivery, good formability, weldability, high corrosion resistance, ${ }^{5}$ and excellent bio-compatibility. But it had the disadvantage of surface roughness and high friction.

Timolium patented vanadium has almost the same frictional resistance and half the stiffness of stainless steel, making it an ideal choice for finishing, aligning as well as leveling and torqueing throughout all phases of treatment. ${ }^{6}$ Titanium-niobium is an innovative archwire designed for precision tooth-tooth finishing. This possesses a formability that lends itself to easy placement of first and second order bends intraorally.

The purpose of this study was to evaluate the surface characteristics and their influence on orthodontic treatment.

\section{AIMS}

The present study was aimed at characterizing and comparing the surface characteristics of the two archwire alloys used commonly in orthodontics, i.e., stainless steel and TMA, with newly introduced timolium and titanium-niobium.

\section{MATERIALS AND METHODS}

This study was conducted to clinically evaluate the changes in surface characteristics of four wires $(16 \times 22$ stainless steel, TMA, timolium, titanium-niobium) with a scanning electron microscope (SEM). ${ }^{7}$ Twenty unused samples were subjected to SEM evaluation and the other twenty samples were placed in the patient's mouth for 3 months and evaluated using SEM. ${ }^{8}$

Each group comprised two subgroups with ten samples per subgroup. Hence, a total of 40 samples were evaluated (Table 1).

Twenty patients were randomly selected, who were undergoing orthodontic treatment with $022 \mathrm{MBT}$ slot and in the leveling phase after aligning the teeth. All 20 samples of stainless steel $16 \times 22$ ( 5 samples), TMA $16 \times 22$ (5 samples), timolium $16 \times 22$ (5 samples), and

Table 1: Type of materials, their size, and manufacturer

\begin{tabular}{lllll}
\hline & & Size & Sample \\
Archwire & Alloy & size $)$ & size & Manufacturer \\
\hline Group I & Stainless steel & $16 \times 22$ & 10 & American ortho \\
Group II & TMA & $16 \times 22$ & 10 & Ormco \\
Group III & Timolium & $16 \times 22$ & 10 & TP ortho \\
Group IV & Titanium-niobium & $16 \times 22$ & 10 & Ormco \\
\hline
\end{tabular}

titanium-niobium $16 \times 22$ (5 samples) were placed in the mouth. Modules were used to hold the archwire in brackets. After 3 months, the wire was removed from the patient's mouth, cleaned under tap water, and stored in the container, and 20 samples of fresh unused wire were obtained from patient's mouth and were evaluated at $500 \times$ magnification using a SEM.

\section{RESULTS}

\section{Scanning Electron Microscope Evaluation of the Surface Topography}

\section{Stainless Steel Unused Wire}

Secondary electron image of the unused $16 \times 22$ rectangular stainless steel wire under $500 \times$ magnification showed an overall smooth surface. The surface of the wires appeared to have a striated appearance, which could be due to the drawing process during the manufacture of the wire. ${ }^{8}$ Occasional dark spots could be viewed, which could be voids that would have occurred during the cooling process of the metal. Randomly placed elevated particles were seen, which could have occurred during the process of finishing. Also, numerous impurities were found plugged onto the surface of the wire (Fig. 1).

\section{Stainless Steel Used Wire}

Secondary electron image of the used $16 \times 22$ rectangular stainless steel wire under 500× magnification showed black hazy patches, which could be interpreted as areas of stress. These patches could have been caused due to wearing of the wire. Also, numerous impurities were found plugged on the surface of the wire ${ }^{9}$ (Fig. 2).

Secondary electron image of the unused $16 \times 22$ rectangular TMA wire under 500× magnification showed multiple small ovoid areas and small craters with fewer

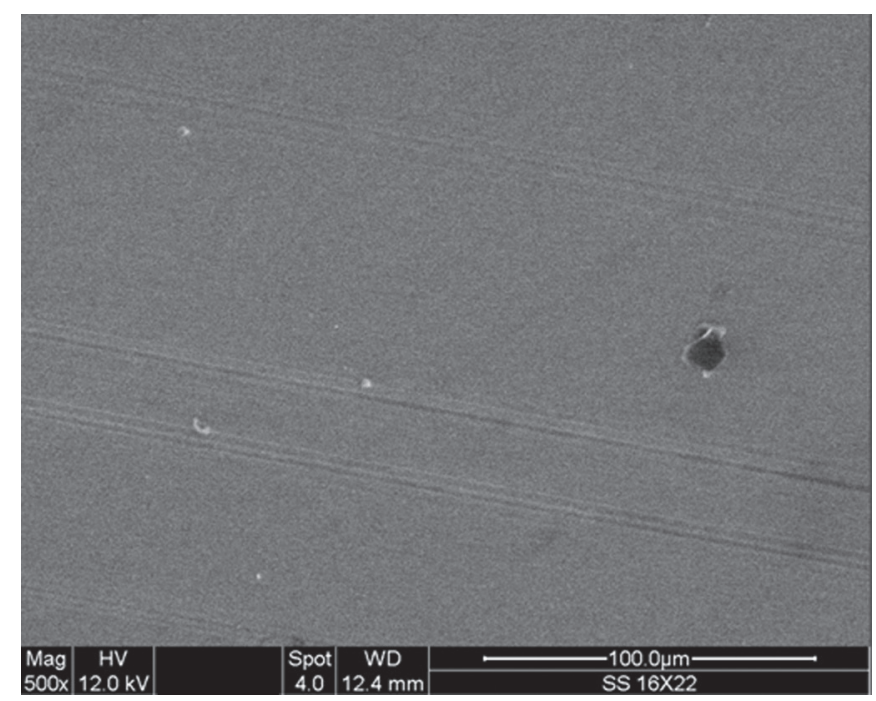

Fig. 1: Surface topography of $16 \times 22$ stainless steel wire 


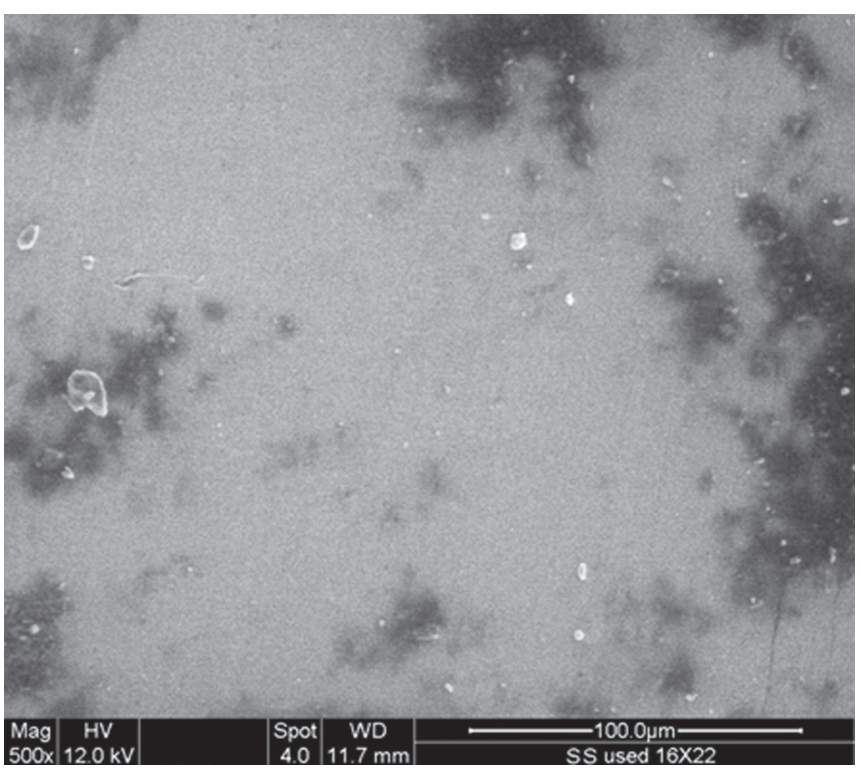

Fig. 2: Surface topography of $16 \times 22$ stainless steel wire after placing it in patient's mouth for 3 months

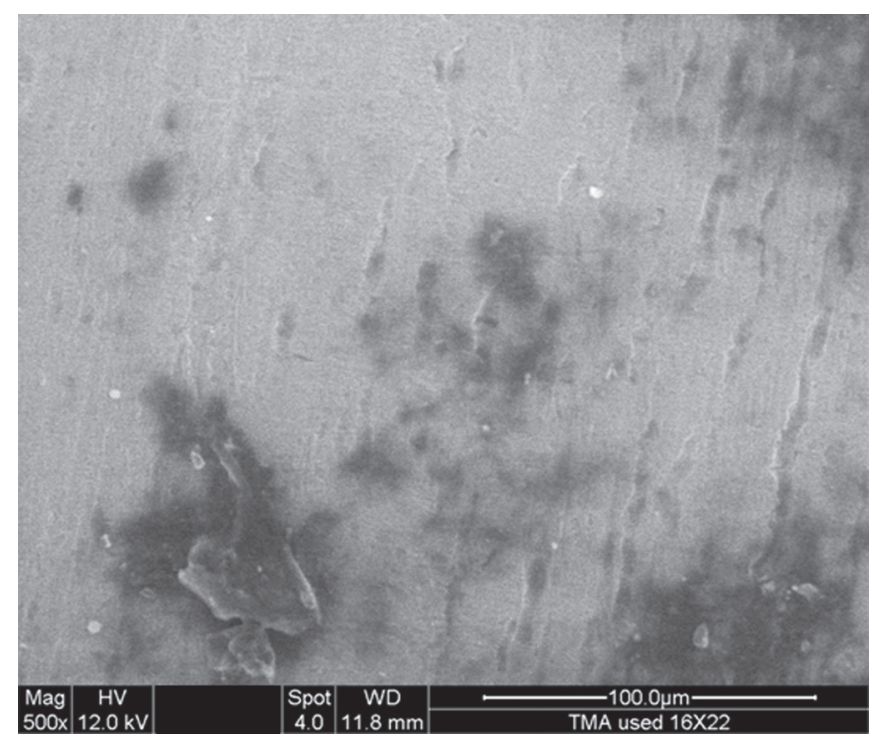

Fig. 4: Surface topography of $16 \times 22$ TMA wire after placing it in patient's mouth for 3 months

elevated regions, which could be attributed to the manufacturing process ${ }^{9,10}$ (Fig. 3).

\section{TMA Used Wire}

Secondary electron image of the used $16 \times 22$ rectangular TMA wire under $500 \times$ magnification showed large areas of stress, which could be seen as black hazy patches and prominent ridges, making the wire rougher. A few white elevated portions were observed, which could be impurities plugged onto the surface of the wire (Fig. 4). ${ }^{9,10}$

\section{Timolium Unused Wire}

Secondary electron image of the unused $16 \times 22$ rectangular timolium wire under 500 $\times$ magnification showed heavy

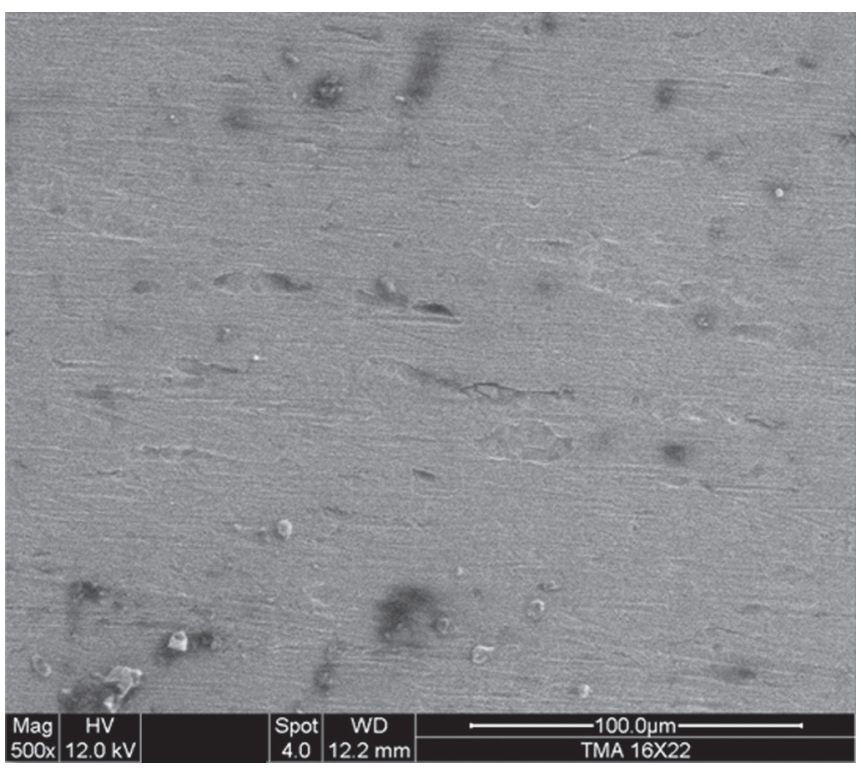

Fig. 3: Surface topography of $16 \times 22$ TMA wire

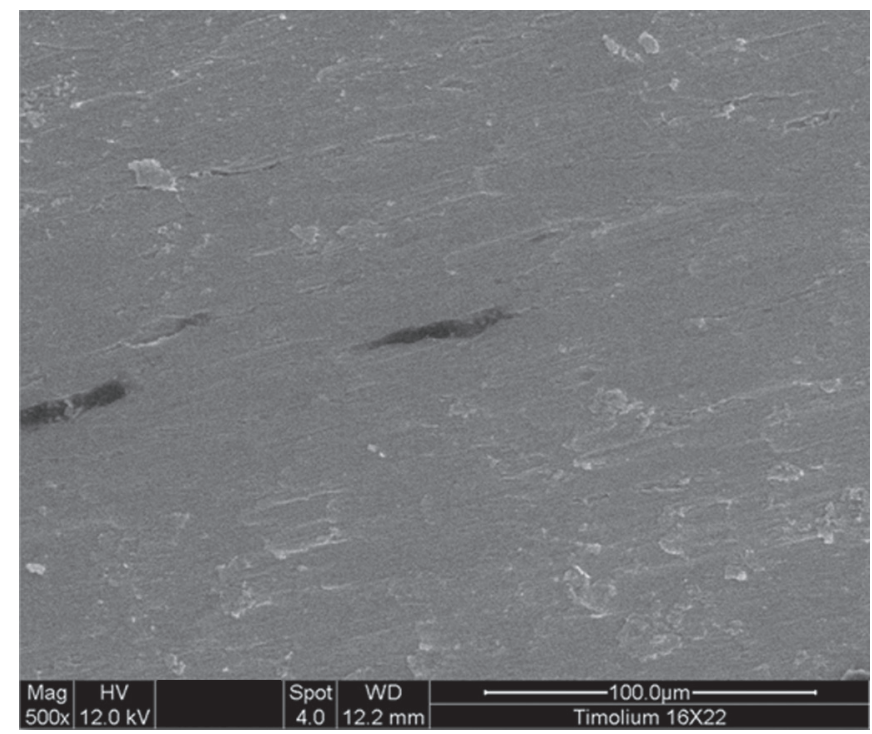

Fig. 5: Surface topography of $16 \times 22$ timolium wire

roughness and voids, which could be due to the nature of manufacturing ${ }^{9}$ (Fig. 5).

\section{Timolium Used Wire}

Secondary electron image of the used $16 \times 22$ rectangular timolium wire under $500 \times$ magnification showed homogenous distribution of deep cracks and craters. Decreased surface roughness was also observed (Fig. 6). ${ }^{9}$

\section{Titanium-niobium Unused Wire}

Secondary electron image of the unused $16 \times 22$ rectangular titanium-niobium wire under $500 \times$ magnification showed uniform prominent striations and ridges with occasional voids, which could be due to the manufacturing process (Fig. 7). ${ }^{6}$ 


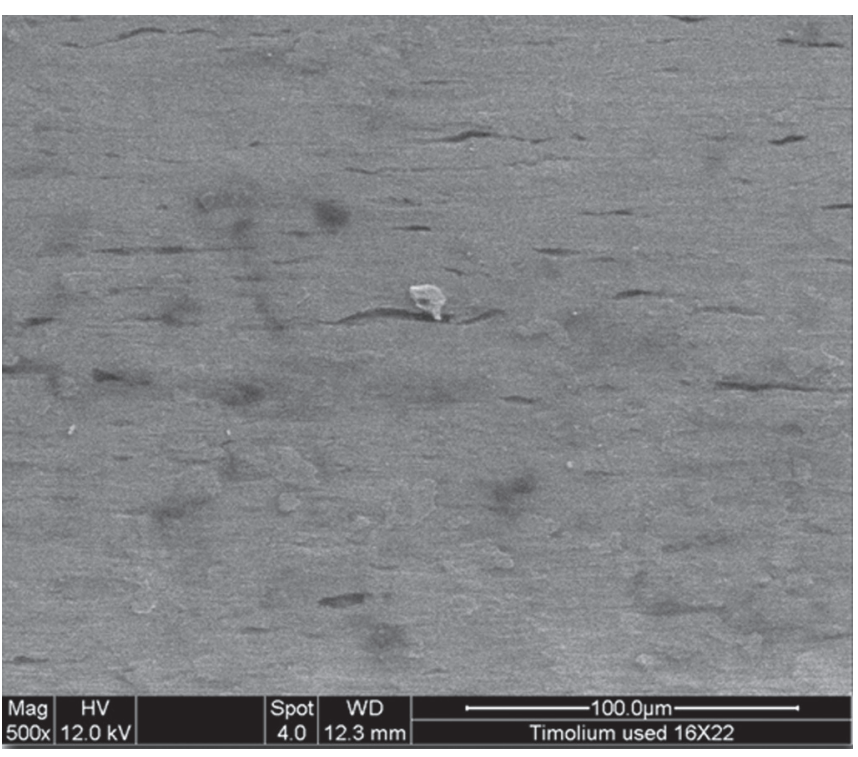

Fig. 6: Surface topography of $16 \times 22$ timolium wire after placing it in patient's mouth for 3 months

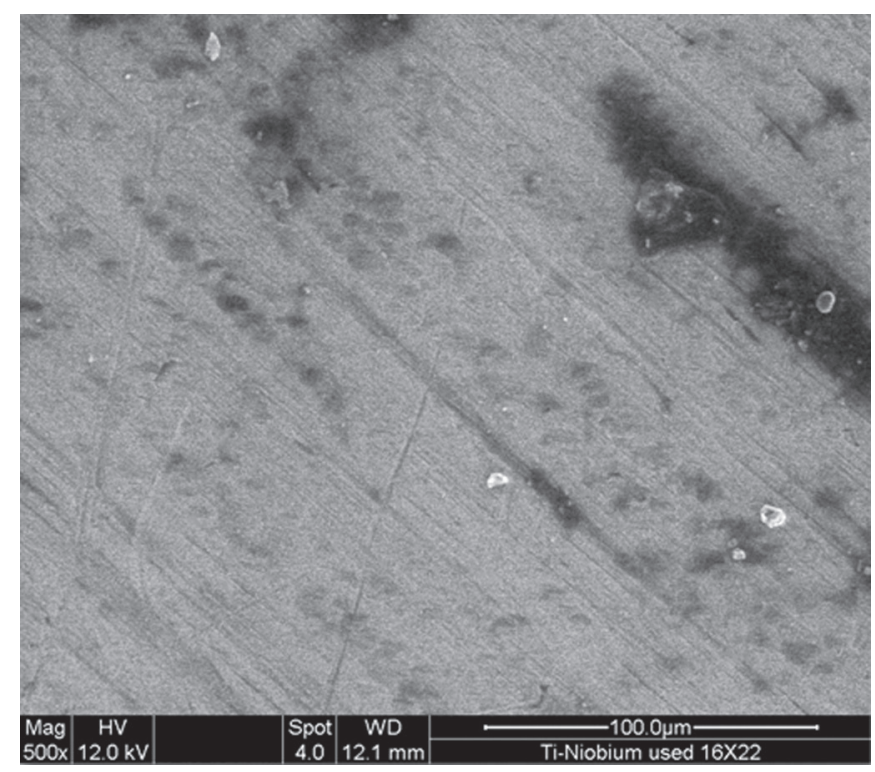

Fig. 8: Surface topography of $16 \times 22$ titanium-niobium wire after placing it in patient's mouth for 3 months

\section{Titanium-niobium Used Wire}

Secondary electron image of the used $16 \times 22$ rectangular titanium-niobium wire under $500 \times$ magnification showed uniform prominent striations and prominent huge voids, which could be interpreted as maximum stress areas. Also, numerous impurities were found plugged onto the surface of the wire (Fig. 8). ${ }^{6}$

\section{DISCUSSION}

Surface evaluation of an archwire alloy is important because of its influence on working characteristics as well as corrosion potential. Scanning electron microscopic evaluation of surface characteristics of the unused $16 \times 22$ rectangular stainless steel wire under $500 \times$ magnification

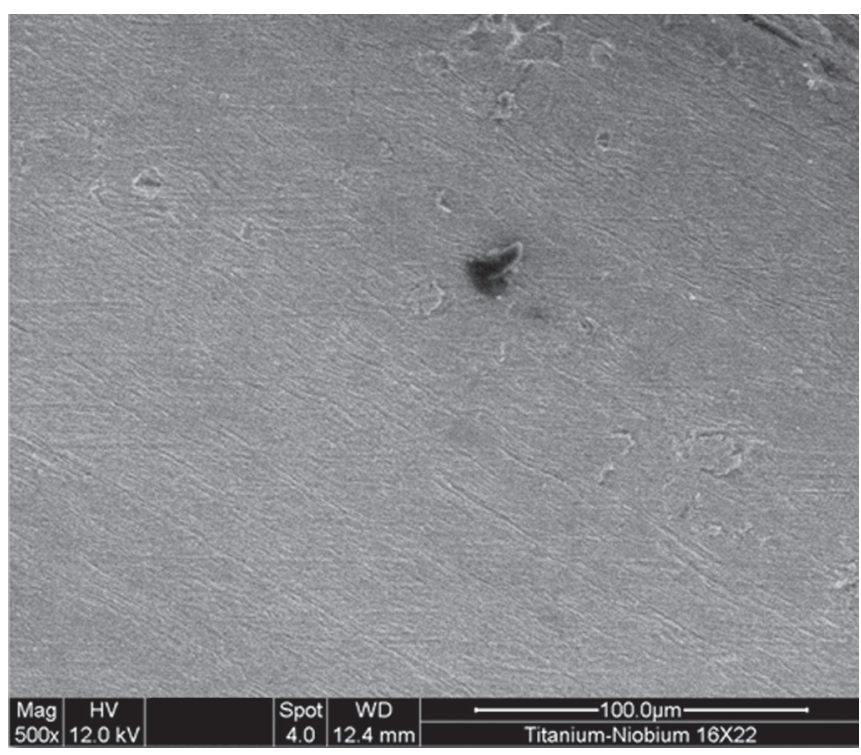

Fig. 7: Surface topography of $16 \times 22$ titanium-niobium wire

showed an overall smooth surface. The TMA archwire showed multiple small ovoid areas and small craters with fewer elevated regions. The timolium archwire showed heavy roughness and voids. The titanium-niobium archwire showed uniform prominent striations and ridges with occasional voids. ${ }^{11}$

Scanning electron microscopic evaluation of surface characteristics of the used $16 \times 22$ rectangular stainless steel wire under $500 \times$ magnification showed black hazy patches, which may be interpreted as areas of stress. ${ }^{4}$ These patches would have been caused due to wearing of the wire. Also, numerous impurities were found plugged on the surface of the wire. The used TMA archwire showed large areas of stress, which could be seen as black hazy patches and prominent ridges, making the wire rougher. ${ }^{12}$ The timolium archwire showed homogenous distribution of deep cracks and craters. Decreased surface roughness is also observed. The used titanium-niobium archwire showed prominent uniform striations and prominent huge voids, which could be interpreted as maximum stress areas. ${ }^{8}$

Although wire characteristics determined by these tests do not necessarily reflect the behavior of the wire under clinical conditions, they provide a basis for comparison of these wires. The characteristics desirable in an orthodontic wire are large spring back, low stiffness, good formability, high stored energy, biocompatibility and environmental stability, low surface friction, and the capability to be welded or soldered to auxiliaries. ${ }^{13,14}$

Titanium molybdenum alloy wires that have the lowest stiffness, good welding characteristics, and high friction compared with the other three alloys can be used for retraction only in frictionless mechanics (retraction loops). The welding of TMA wire auxiliaries of the same or different cross sections to the archwire can further increase archwire versatility. 
Timolium appears to be an intermediate wire between stainless steel and TMA. When compared with TMA, it is more resilient with low friction. Timolium with its mechanical properties compared with stainless steel could replace stainless steel wires in certain clinical situations and could be used popularly in friction mechanics. When compared with stainless steel, Timolium has more friction and less stiffness.

Stiffness of titanium-niobium is roughly half of that of stainless steel. This wire has the advantage of not having the range of activations of TMA but slightly more stiffness than TMA. Possessing a formability that lends itself to easy placement of first- and second-order bends intraorally, without producing very high forces, thereby reducing the possibility of delaminating the bracket, titanium-niobium wires could be considered precisely as finishing wires.

\section{CONCLUSION}

Scanning electron microscopic evaluation of surface characteristics of the unused $16 \times 22$ rectangular stainless steel wire under 500× magnification showed an overall smooth surface. Titanium molybdenum alloy archwire showed multiple small ovoid areas and small craters with fewer elevated regions. Timolium archwire showed heavy roughness and voids. Titanium-niobium archwire showed uniform prominent striations and ridges with occasional voids.

Scanning electron microscopic evaluation of surface characteristics of the used $16 \times 22$ rectangular stainless steel wire under 500× magnification showed black hazy patches, which may be interpreted as areas of stress. These patches would have been caused due to wearing of the wire. The used TMA archwire showed large areas of stress, which could be seen as black hazy patches and prominent ridges, making the wire rougher. Timolium archwire showed homogenous distribution of deep cracks and craters. Decreased surface roughness is also observed. The used titanium-niobium archwire showed prominent uniform striations and prominent huge voids, which could be interpreted as maximum stress areas.

\section{REFERENCES}

1. Berradja A, Willems G, Celis JP. Tribological behaviour of orthodontic archwires under dry and wet sliding conditions in-vitro. I-Frictional behaviour. Aust Orthod J 2006 May;22(1): 11-19.

2. Kusy RP. A review of contemporary archwires: their properties and characteristics. Angle Orthod 1997 Jun;67(3): 197-208.

3. Burstone CJ, Goldberg AJ. Beta-titanium: a new orthodontic alloy. Am J Orthod Dentofacial Orthop 1980 Feb;77(2):121-132.

4. Edie JW, Andreasen GF, Zaytoun MP. Surface corrosion of Nitinol and stainless steel under clinical conditions. Angle Orthod 1981 Oct;51(4):319-324.

5. Kapila S, Sachdeva R. Mechanical properties and clinical applications of orthodontic wires. Am J Orthod Dentofacial Orthop 1990 Dec;96(2):100-109.

6. Dalstra M, Denes G, Melsen B. Titanium-niobium, a new finishing wire alloy. Clin Orthod Res 2000 Feb;3(1):6-14.

7. Kusy RP, Whitley JQ, Gurgel JDA. Comparisons of surface roughness and sliding resistances of 6 titanium based or TMA-type archwires. Am J Orthod Dentofacial Orthop 2004 Nov;126(5):589-603.

8. Kononen MHO, Lavonius ET, Kivilahti JK. SEM observations on stress corrosion cracking of commercially pure titanium in a topical fluoride solution. Dent Mater 1995 Jul;11(4): 269-272.

9. Vinod Krishnan, Jyothindra Kumar K. Mechanical properties and surface characteristics of three arch wire alloys. Angle Orthod 2004 Dec;74(6):825-831.

10. Nakagawa M, Matsuya S, Udoh K. Corrosion behavior of pure titanium and titanium alloys in fluoride-containing solutions. Dent Mater J 2001 Dec;20(4):305-314.

11. Bourauel C, Fries T, Drescher D, Plietsch R. Surface roughness of orthodontic wires via atomic force microscopy, laser specular reflectance, and profilometry. Eur J Orthod 1998 Feb;20(1):79-92.

12. Kaneko K, Yokoyama K, Moriyama K, Asaoka K, Sakai J. Degradation in performance of orthodontic wires caused by hydrogen absorption during short term immersion in $2.0 \%$ acidulated phosphate fluoride solution. Angle Orthod 2004 Aug;74(4):487-495.

13. Kusy RP, Whitley JQ, Mayhew MJ, Buckthal JE. Surface roughness of orthodontic archwires via laser spectroscopy. Angle Orthod 1988 Jan;58(1):33-45.

14. Mayhew MJ, Kusy RP. Effects of sterilization on the mechanical properties and the surface topography of nickeltitanium arch wires. Am J Orthod Dentofacial Orthop 1988 Mar;93(3):232-236. 